\title{
Analytical Modeling of a Permanent-Magnet Synchronous Machine in a Flywheel
}

\author{
S. R. Holm ${ }^{1}$, H. Polinder ${ }^{2}$, and J. A. Ferreira ${ }^{2}$, Fellow, IEEE \\ ${ }^{1}$ North-West University, Potchefstroom 2520, South Africa \\ ${ }^{2}$ Delft University of Technology, Delft, CD 2628, The Netherlands
}

\begin{abstract}
We develop an analytical model for a radial-flux external-rotor permanent-magnet synchronous machine (PMSM) without slots in the stator iron and with a shielding cylinder. The machine is part of an energy storage flywheel, to be used as the peak-power unit in a hybrid electric passenger bus. To reduce the induced no-load losses due to the high rotational speed of the flywheel, the slots in the stator are made not of iron but of a nonmagnetic plastic material. This results in an air gap winding with a stator yoke consisting of stacked circular laminations. The analytical model includes the effect of the winding distribution on the field, the fact that it is in the air gap, and the effect of the eddy-current reaction field of the shielding cylinder. The two-dimensional magnetic field is solved in six defined machine layers and useful machine quantities are derived directly from it, leading to the machine voltage equation. We built a prototype flywheel machine. The locked-rotor machine resistance and inductance predicted by the analytical model was compared with the experimentally determined values. The values showed good agreement, thereby validating the analytical model of the machine.
\end{abstract}

Index Terms-Analytical modeling, energy storage, flywheels, permanent-magnet machines.

\section{INTRODUCTION}

\section{A. Background}

$\mathbf{H}$ YBRID electric vehicles require a much lower energy density from their electrical energy storage technology than pure electric vehicles [1], [2]. A high power density of the energy storage technology is, however, crucial in hybrids. Careful design to minimize the overall storage losses in the energy storage system is therefore required, since higher losses lead to a lower power density.

In the project leading to this paper, a production prototype of a flywheel energy storage system was developed and built. This energy storage system was designed for use as the peakpower unit in a hybrid electric city bus. The feasibility of using the flywheel energy storage technology for this application as opposed to other energy storage technologies has been shown in [2].

An interesting aspect of the storage system was the design and optimization of the electrical machine integrated into the flywheel. This machine had to have low no-load and full-load losses and a high power density. The electromagnetic aspects of this machine are the focus of this paper.

The structure and build-up of the machine are motivated as follows: The maximum energy density of a flywheel is given by [3]

$$
\hat{e}_{v}=K \sigma_{\min } \quad\left[\mathrm{J} / \mathrm{m}^{3}\right]
$$

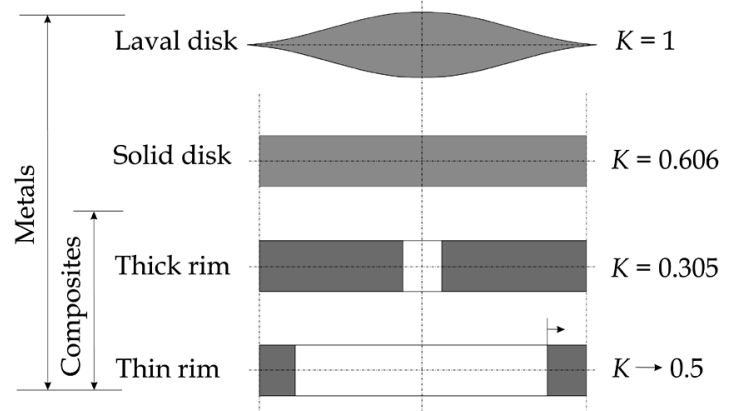

Fig. 1. Four different flywheel shapes.

and the maximum specific energy

$$
\hat{e}_{m}=K \frac{\sigma_{\min }}{\rho} \quad[\mathrm{J} / \mathrm{kg}]
$$

where $K$ is the shape factor of the flywheel, related to the mass moment of inertia $J ; \sigma_{\min }$ is the minimum required tangential strength of the flywheel material; and $\rho$ is the mass density of the material.

From (1) we see that to reach as high an energy density as possible, the shape factor and the tangential strength of the material should be maximized. For a high specific energy, from (2) we see that in addition to the requirements for a high energy density, the mass density should be as low as possible.

Fig. 1 shows four different flywheel shapes with their respective shape factors. The upper two geometries require an isotropic material (in terms of their mechanical strength properties) due to the direction of the forces on the material. The lower two geometries may be built from a material with anisotropic strength properties like carbon fiber. A geometry similar to the last two provides for easy integration of the composite flywheel and the 


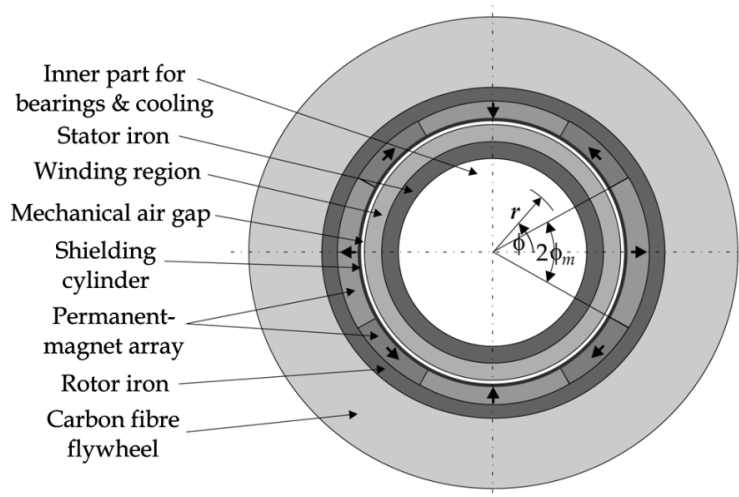

Fig. 2. Radial cross section of the flywheel machine.

electrical machine, and is therefore chosen. The latter is simply placed inside the unused space on the inside of the flywheel.

For the chosen flywheel geometry, the logical choice of the flux direction is radial since the available area for an axial flux direction is limited. (A metal flywheel machine is better suited to an axial flux topology since in this case, the available area for the flux is much larger in that direction. See [4] and [5] for examples of metal flywheels with an axial flux machine topology.)

Permanent magnets are chosen as the field excitation source since it leads to the highest air gap flux density per unit excitation loss than other excitation types.

In a predecessor of the machine under discussion in this paper, a conventional slotted stator was implemented [6]. This led to very high stator losses. These losses are mainly located in the stator slots, and therefore a logical choice for the machine was to remove the metal slots and replace them with a plastic material. (See [7] for a comparison between slotted and slotless stators; the paper concludes with a strong argument for the latter.) Since in a slotted stator the conductors lie directly in the magnetic field, Litz wire is used to minimize eddy current losses in the stator conductors.

The last part of the machine structure that needs to be motivated is the shielding cylinder. The effect of a shielding cylinder on the rotor losses in permanent-magnet machines has been investigated in [8]-[11] and [12], among others. This cylinder shields the permanent magnets and the rotor iron from high-frequency magnetic fields originating from the stator currents. One general conclusion was that for low rotational speeds, the addition of a shielding cylinder increases the losses, while for high rotational speeds, the addition of a shielding cylinder reduces them. In [10], it is furthermore recommended that when solid rotor iron is used (as is the case in this flywheel machine), a shielding cylinder should always be used to reduce the rotor losses.

From the above motivation, the electrical machine was chosen to be a radial-flux external-rotor permanent-magnet synchronous machine (PMSM) without slots in the stator iron and with a shielding cylinder. A radial cross section of the machine is shown in Fig. 2.

On the inside of the stator iron is an electromagnetically inactive area that is used for bearings, cooling, and other auxiliaries. The stator iron consists of a slotless cylinder that is lam- inated, i.e., it consists of very thin, closely stacked rings. On its outside, the stator winding region is located. On the outside of the mechanical air gap the electromagnetic shielding cylinder is located, followed by the permanent-magnet array and the solid rotor iron yoke. On the outside of the rotor iron, the carbon fiber flywheel is mounted.

\section{B. Motivation for Use of the Analytical Method}

The analytical model presented in this paper is quite complex and one has to ask oneself if it is worth the substantially greater initial effort compared to the finite-element method (FEM). The analytical approach is believed to be a sensible choice because:

It requires lower computation time. Although modern computers are much faster than a few decades ago when the difference in computation time between the analytical method and the FEM was quite substantial, this reason remains valid today. This is especially true when parameterized solutions have to be done requiring machine dimension changes. In the FEM, this requires re-meshing for each iteration, whereas in the analytical method a simple calculation will suffice.

The machine geometry is well-suited for an analytical approach. The slotless structure of the winding makes permeability variations something that only has to be considered in the radial direction. This simplifies the boundary conditions and makes the analytical method easier to handle.

The analytical approach gives greater insight into the problem. Stoll first used this argument, which is still valid today, in his textbook on eddy-current analysis [13]. The reason for the greater insight is that dependencies can be seen simply by inspection: for example, the no-load voltage's dependency on the ratio of certain machine radii. This provides transparency-something that is completely absent in the finite-element method.

\section{Objective}

The objective of this paper is to present a comprehensive analytical model of the flywheel permanent-magnet machine of Section I-A. The next two subsections will conclude the introduction by presenting a literature review (from which the originality of the analytical model will be shown) and a paper outline.

\section{Literature Review}

1) Permanent-Magnet Field: Analytical field calculations are not new. In fact, the 2-D solution to Poisson's equation has been known since early in the previous century [14]. However, since the availability of high energy product rare-earth permanent magnets like Samarium Cobalt (SmCo) in the 1970s and Neodymium Iron Boron (NdFeB) in the 1980s, the analytical calculation of the magnetic field in permanent-magnet-excited machines has received renewed interest in recent literature. Before these magnets were in use in machines, the air gaps were small and one-dimensional field calculations were adequate. These rare-earth permanent magnets resulted in larger useable air gaps since their coercive force is so high. These large air gaps resulted in curvature effects of the field and therefore one-dimensional analysis was no longer adequate.

For recent literature see, for example, [15]-[18], [10], [19], [20] and [21] for a description of the analytical calculation of the 
2-D B-field in permanent-magnet machines in cylindrical coordinates due to radially magnetized permanent magnets, and [22] in Cartesian coordinates. In [15], [19], [20], and [22], equivalent surface current densities are used to replace the permanent magnets, while in [16]-[18] and [10] the magnetization is used directly.

In [17], the permanent magnets are considered to be surface mounted, as in [15], [16], [18], [10], [19], [20], and [22]. Zhu et al. wrote [17] as the first part of a four-part series devoted to the analytical calculation of magnetic fields in permanent-magnet machines. As already mentioned, the first part describes the field due to the magnets. The other three parts consider the magnetic field due to the stator currents [23], the effects of stator slotting on the field [24], and the combination of fields due to the magnets and stator currents, resulting in the field in a loaded machine [25]. In [26], Zhu et al. further develop their analytical model to predict the magnetic field due to inset magnets. In [27], several improvements on [17] are documented: internal and external rotors are now included in their model, as well as both radial and parallel magnetization. (The field due to both radial and parallel magnetization has also been solved in [15].)

Watterson et al. developed an analytical field calculation model specifically as an optimization tool for a machine with a solid permanent-magnet rotor and slotless stator [16]. Kim et al. discussed the solution of the 2-D magnetic field in cylindrical coordinates in a machine with rotor eccentricity in [18]. In [28], they included the stator slotting effect on the field in the model. Zhilichev [21] combines analytical field calculations with corrections from the finite element method where necessary, resulting in a hybrid method. Both slotless and slotted stators are included, although the emphasis is on the treatment of the slots.

In [15], [17], [21], [23]-[27], and [28], the magnetic scalar potential is used to obtain the magnetic field of the magnets, while in [16], [10], [19], and [22], the magnetic vector potential is used. In [20], a combination of both approaches is used.

2) Stator Current Field: Two aspects in the calculation of the stator current field relevant to the machine discussed in this paper are: (a) field calculation where excitation is by means of a slotless winding (an air gap winding) and (b) the calculation of eddy-current reaction fields. The available literature addressing these two issues include the following.

a) Air Gap Winding Excitation: First, several researchers have calculated the magnetic field in the air gap of machines with slotted stators due to the stator currents; these are, among others, [23] (with improvements in [27]), [29] and [30]. The approach here is to use an equivalent surface current density located at the stator surface. For a slotless stator (i.e., an air gap winding), this approach is not valid, and the field due to the current density in the air gap needs to be calculated directly. Two authors that did this are Atallah et al. [31] and Sridhar [32].

b) Eddy-Current Reaction Fields: In the 1960s and 1970s, several textbooks on analytical solutions in electromagnetics were published. Some of these authors also addressed eddy currents, like Lammeraner [33] and Stoll [13]. Since then, many other publications have also addressed the analytical calculation of the magnetic field due to eddy currents. See for example [34]-[38], [12], and [39]. Some of the works cited presented their results in Cartesian coordinates ([33], [13], [35] and [38]), while [34], [36], [37], [12], and [39] presented them in cylindrical coordinates, thereby also accounting for curvature effects.

\section{E. Originality of the Analytical Model Presented in This Paper}

The previous section presented a literature review of analytical models for the field due to the permanent magnets and stator currents in PMSMs. At first sight, the topic seems to have been treated extensively in literature and therefore that no contribution can be made. However, upon closer inspection one discovers that the combination of the (a) stator current field for a slotless stator and (b) the reaction field of the eddy currents in the shielding cylinder has not been presented in literature yet. The field solution for this combination requires a six-layer system (as will be shown in Section II). None of the publications cited above solves a six-layer system; the highest number of layers previously presented is five.

\section{F. Paper Outline}

The paper is structured as a logical buildup to the experimental results of Section VI, which validates the analytical model. The starting point is the Poisson equation, and the method to solve it is presented in Section II. The solution is presented in Sections III and IV for the magnetic field of the permanent magnets and stator currents, respectively. The voltage equations of Section $\mathrm{V}$ follow directly from the fields by utilizing a simple relation between the flux linkage and the magnetic vector potential (that will be presented in Section II-F). The voltage equations are followed by a presentation of the experimental results in Section VI, whereafter the paper ends with the conclusions in Section VII.

\section{SOLUTION METHOD}

The magnetic vector potential is used in this paper to find the magnetic field. The scalar potential could also have been used: the vector potential is simply a choice of preference. (The vector potential does have some advantages. For example, Section II-F will show that the flux linkage of a coil can be written directly as a simple expression in terms of the magnetic vector potential A.)

\section{A. Stator and Rotor Coordinate Systems}

In this paper, two coordinate systems are used: see Fig. 3 . Both are cylindrical coordinate systems; however, one is fixed to the rotor and the other to the stator. The rotor coordinate system is denoted with the coordinates $(r, \phi)$ and that of the stator by $(r, \varphi)$.

The rotor positional angle $\theta$ is introduced as the angle between the $(r, \phi)$-system and $(r, \varphi)$-system as

$$
\theta \equiv \varphi-\phi
$$

The $(r, \phi, z)$-system rotates at a mechanical angular velocity of $\omega_{m}$ with respect to the $(r, \varphi, z)$-system, or

$$
\theta(t)=\int \omega_{m} d t+\theta_{0}=\omega_{m} t+\theta_{0}
$$

where $\theta_{0}$ is the initial rotor position. 


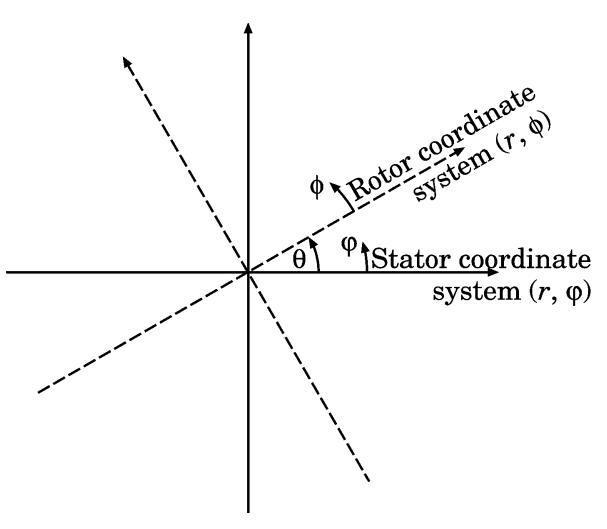

Fig. 3. Stator and rotor coordinate systems.

\section{B. List of Assumptions}

In the rest of the work presented in this paper, the following assumptions were made.

1) A two-dimensional solution in cylindrical coordinates is assumed to be sufficient, i.e., $\mathbf{B}=B_{r} \hat{\mathbf{i}}_{r}+B_{\phi} \hat{\mathbf{i}}_{\phi}$. This implies that the magnetic vector potential has only a $z$-component: $\mathbf{A}=A_{z} \hat{\mathbf{i}}_{z}$.

2) $\mathbf{A}$ and $\mathbf{B}$ do not depend on $z$, i.e., $\mathbf{A}=\mathbf{A}(r, \phi)$ and $\mathbf{B}=$ $\mathbf{B}(r, \phi)$.

3) linearity, i.e., the vector potentials of different sources may simply be added together algebraically: $\mathbf{A}_{\text {total }}=$ $\mathbf{A}_{\text {magnets }}+\mathbf{A}_{\text {stator currents; }}$;

4) symmetry, i.e., $\mathbf{A}(r, \phi)=-\mathbf{A}(r, \phi+(\pi / p))$; where $r$ and $\phi$ are the radial and rotor angular coordinates, respectively, and $p$ is the number of pole pairs;

5) the relative permeability of the stator and rotor iron is infinite, i.e., it does not saturate;

6) the relative permeability of all non-iron parts (the winding, the shielding cylinder and the magnets) is equal to 1.0 ;

7) The remanent flux densty of the permanent magnets is proportional to $1 / r ;$

8) the magnets do not demagnetize; and

9) all materials are isotropic.

The list may seem rather restrictive, but comparison with the experimental results in Section VI shows that not much is lost in terms of accuracy.

\section{The Six Machine Layers}

The assumptions listed in Section II-B give rise to the definition of the cylindrical coordinate system as shown in Fig. 4. The figure also shows the definition of the machine radii and the six layers making up the machine.

Layer 1 is the slotless laminated stator iron; layer 2 is the winding; layer 3 is the mechanical air gap; layer 4 is the shielding cylinder; layer 5 is the permanent-magnet layer and layer 6 is the solid rotor iron.

\footnotetext{
${ }^{1}$ The reason for this assumption is that it greatly simplifies the particular solution (21) of the Poisson equation: it does not depend on $r$ in this case, only on
} $\phi$.

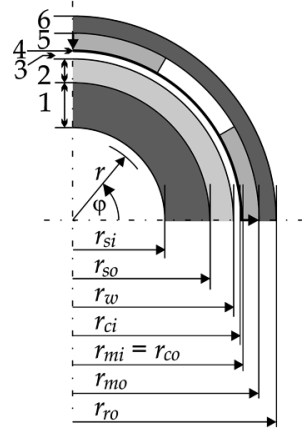

Fig. 4. A quarter cross section of the flywheel machine for the analytical calculation of the magnetic field, showing the six defined layers.

\section{Derivation of the Vector Form of Poisson's Equation}

As with most electromagnetic problems in electrical machines, we start from the Maxwell field equation for the magnetoquasistatic (MQS) approximation:

$$
\begin{aligned}
& -\nabla \times \mathbf{H}+\mathbf{J}=-\mathbf{J}_{\text {ext }} \\
& \nabla \times \mathbf{E}+\frac{\partial \mathbf{B}}{\partial t}=\mathbf{0} \\
& \nabla \cdot \mathbf{J}_{\text {ext }}=0
\end{aligned}
$$

and

$$
\nabla \cdot \mathbf{B}=0
$$

where the symbols have their customary meaning: $\mathbf{H}$ is the magnetic field intensity, $\mathbf{J}$ is the current density, $\mathbf{J}_{\text {ext }}$ is the external current density, $\mathbf{E}$ is the electric field intensity, and $\mathbf{B}$ is the magnetic flux density. The static part is given by (5a) and the dynamic part by $(5 b)$.

The constitutive relations for a linear isotropic medium are

$$
\mathbf{J}=\sigma \mathbf{E}
$$

where $\sigma$ is the conductivity (Ohm's law), and

$$
\mathbf{B}=\mu \mathbf{H}+\mathbf{B}_{\text {rem }}
$$

where $\mu \equiv \mu_{0} \mu_{r}$ is the permeability ( $\mu_{0}$ is the permeability of free space) and $\mathbf{B}_{\text {rem }}$ is the remanent flux density of the permanent magnets.

By use of (6b), Ampère's law (5a) can be rewritten as

$$
\nabla \times \mathbf{B}=\mu \mathbf{J}+\mu \mathbf{J}_{\text {ext }}+\nabla \times \mathbf{B}_{\text {rem }} .
$$

Since B is solenoidal from (5d), it can be written in terms of the vector potential as

$$
\mathbf{B}=\nabla \times \mathbf{A}
$$


To completely specify $\mathbf{A}$, we have to state its divergence (this is called gauging). We choose the Coulomb gauge

$$
\nabla \cdot \mathbf{A}=0 .
$$

By subtitution of (8) into (7) and recalling the vector identity

$$
\nabla \times(\nabla \times \mathbf{A})=\nabla(\nabla \cdot \mathbf{A})-\nabla^{2} \mathbf{A}
$$

we have

$$
-\nabla^{2} \mathbf{A}=\mu \mathbf{J}+\mu \mathbf{J}_{\text {ext }}+\nabla \times \mathbf{B}_{\text {rem }}
$$

where (9) was also used. The final step is to substitute the constitutive relation (6a) in conjunction with

$$
\mathbf{E}=-\frac{\partial \mathbf{A}}{\partial t}
$$

into (11). This results in

$$
-\nabla^{2} \mathbf{A}+\mu \sigma \frac{\partial \mathbf{A}}{\partial t}=\mu \mathbf{J}_{s}+\nabla \times \mathbf{B}_{\mathrm{rem}}
$$

where the external current density $\mathbf{J}_{\text {ext }}$ has been renamed to the stator current density $\mathbf{J}_{s}$.

\section{E. Boundary Conditions}

In order to solve for $\mathbf{A}$ from (13), we set up boundary value problems by writing boundary condition equations for the layers shown in Fig. 4. The two relevant boundary conditions are those implied by Ampère's law and the flux conservation law.

The boundary condition implied by Ampère's law (5a) states that the tangential component of the magnetic field intensity on one side of the boundary is equal to that of the other side plus a surface current density, or mathematically [40]

$$
\hat{\mathbf{n}} \times\left(\mathbf{H}^{(\nu)}-\mathbf{H}^{(\nu+1)}\right)=\mathbf{K}^{(\nu)}
$$

where $\hat{\mathbf{n}}$ is the unit normal vector, $\mathbf{H}^{(\nu)}$ denotes the magnetic field intensity in region $\nu$ and $\mathbf{K}^{(\nu)}$ the surface current density at the boundary interface between regions $\nu$ and $\nu+1$.

The boundary condition implied by the magnetic flux conservation law (5d) states that the normal component of the flux density on one side of a region boundary is equal to that on the other, or mathematically

$$
\hat{\mathbf{n}} \cdot\left(\mathbf{B}^{(\nu)}-\mathbf{B}^{(\nu+1)}\right)=0 .
$$

\section{F. Linked Flux}

As shown in [30] and [40], by the use of Stokes' integral theorem, one can obtain the flux linkage of a coil directly from the magnetic vector potential. From (8) and Stokes' integral theorem, we may write for the flux linkage

$$
\lambda=\iint_{S} \mathbf{B} \cdot d \mathbf{a}=\iint_{S} \nabla \times \mathbf{A} \cdot d \mathbf{a}=\oint_{C} \mathbf{A} \cdot d \mathbf{s}
$$

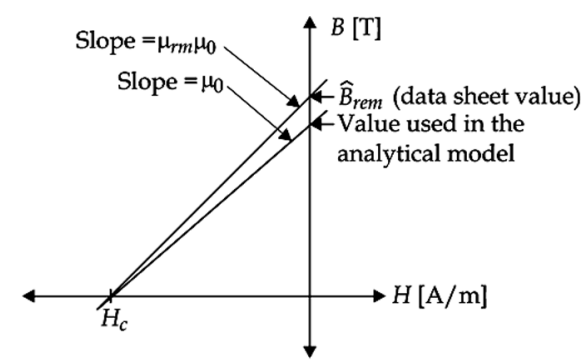

(a)

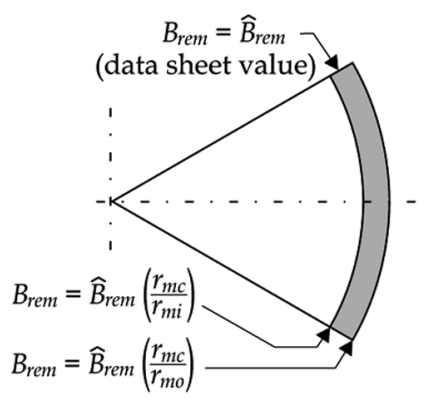

(b)

Fig. 5. Setting of the value of the remanent flux density: (a) $\hat{B}_{\text {rem }}$ setting 1: due to the difference in $\mu_{r m}$ of the magnets in reality and in the analytical model; (b) $\hat{B}_{\text {rem }}$ setting 2: due to the assumption that $B_{\text {rem }} \propto(1 / r)$.

where $C$ is the closed contour forming a boundary for $S$, i.e., the contour $C$ follows along the conductor making up the coil.

Since A has only a $z$-component which is constant in that direction, the contour integrals along the parts of curve $C$ in (16) along the $Z$-axis are equal to the value of $A_{z}$ at that particular value of $r$ and $\varphi$, times $l_{s}$, the stator axial length (stack length). Therefore, the total flux linked by a single full-pitch turn at a radius $r$ and angle $\varphi$ is simply

$$
\lambda_{t}(r, \varphi)=2 l_{s} A_{z}(r, \varphi) .
$$

\section{Field of the Permanent Magnets}

\section{A. The Value of the Remanent Flux Density}

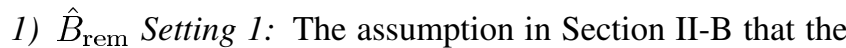
relative permeability of the permanent magnets is equal to 1.0 was made to simplify the analytical field calculations. The resulting air gap flux density can be adjusted for a realistic relative permeability of larger than 1.0 (typically $\mu_{r m}=1.05$ for $\mathrm{NdFeB}$ ) by using a lower remanent flux density in the calculation. This lower value is obtained as follows: first, a line is drawn from the point $\left(H_{c}, 0\right)$ (on the $B-H$ curve of the permanent magnet) with a slope of $\mu_{0}$ [see Fig. 5(a)]. The value of $B$ that is obtained where this line intersects the $B$-axis results in a realistic value for $\hat{B}_{\text {rem }}$.

2) $\hat{B}_{\text {rem }}$ Setting 2: To simplify the analytical field calculations, another assumption was made in Section II-B: $\mathbf{B}_{\text {rem }}$ was assumed to be proportional to $1 / r$. This is of course not true in a permanent magnet in reality, but the simplifying assumption is reasonable since the magnets are relatively thin. If a constant remanent flux density were to be used in the analytical calculations, the particular solution of the vector potential 
would be proportional to $r$ and contain a term $1 /\left((k p)^{2}-1\right)$ for $k p \neq 1$ calculation. (In [17], this solution was used.) When $B_{\text {rem }} \propto(1 / r)$ is assumed, the particular solution is independent of $r$ and valid for all $k p$. The latter option is simpler and thus chosen in the solution presented here. To remedy the effect of this assumption on the resulting air gap flux density, $\hat{B}_{\text {rem }}$ is chosen to be the data sheet value in the center of the magnets, as shown in Fig. 5(b).

\section{B. The Poisson Equation for PM Excitation}

When solving for the magnetic field due to the permanent magnets only, the terms $\mathbf{J}_{s}$ and $\partial \mathbf{A} / \partial t$ in (13) are set to zero. By use of assumptions 1 and 2 in Section II-B, the Poisson equation (13) becomes

$$
\begin{aligned}
\frac{\partial^{2} A_{z}}{\partial r^{2}}+\frac{1}{r^{2}} \frac{\partial^{2} A_{z}}{\partial \phi^{2}} & +\frac{1}{r} \frac{\partial A_{z}}{\partial r} \\
= & -\frac{B_{\mathrm{rem}, \phi}}{r}-\frac{\partial B_{\mathrm{rem}, \phi}}{\partial r}+\frac{1}{r} \frac{\partial B_{r e m, r}}{\partial \phi}
\end{aligned}
$$

in cylindrical coordinates. Equation (18) can be used to solve for $A_{z}$ for any arbitrary configuration of permanent magnets. This is because the remanent flux density vector can be in any direction or combination of directions described by its $r$ - and $\phi$-components. In [2], discrete and continuous Halbach arrays were investigated by use of (18). In this paper, however, only results for the radial array (with magnetization in the $r$-direction only) will be presented. The terms $B_{\text {rem }, \phi} / r$ and $\partial B_{\text {rem, } \phi} / \partial r$ in (18) are therefore zero.

The six regions (layers) in the machine are denoted by $\nu$ and counted from the inside out (see Fig. 4). The only region where there is a magnetic field source is the permanent-magnet region $(\nu=5)$. In the other five regions, the Poisson equation (18) simplifies to the corresponding Laplace equation

$$
\frac{\partial^{2} A_{z}}{\partial r^{2}}+\frac{1}{r^{2}} \frac{\partial^{2} A_{z}}{\partial \phi^{2}}+\frac{1}{r} \frac{\partial A_{z}}{\partial r}=0
$$

1) Solution in the Air Gap: Solutions to (18) and (19) are well-documented in literature. In this paper, a sum of solutions over the space harmonics $k$ is used.

The solution to (19) is

$$
A_{z}^{(\nu)}(r, \phi)=\sum_{k=1,3,5, \cdots}^{\infty} \hat{A}_{z, k}^{(\nu)}(r) \sin (k p \phi)
$$

where

$$
\hat{A}_{z, k}^{(\nu)}(r)=C_{k}^{(\nu)}\left(\frac{r}{r_{\nu}}\right)^{-k p}+D_{k}^{(\nu)}\left(\frac{r}{r_{\nu}}\right)^{k p}
$$

and $C_{k}^{(\nu)}$ and $D_{k}^{(\nu)}$ are the boundary condition constants. In (20b), $r_{\nu}$ is the radius between layers $\nu$ and $\nu+1$. (Since the permanent magnets form layer $5,(20)$ is valid for $\nu=1,2,3,4$, and 6.)

2) Solution in the PM Region: In the solution to Poisson's equation (18), (20) forms a homogeneous part of the solution. The particular solution still has to be obtained. It is assumed that

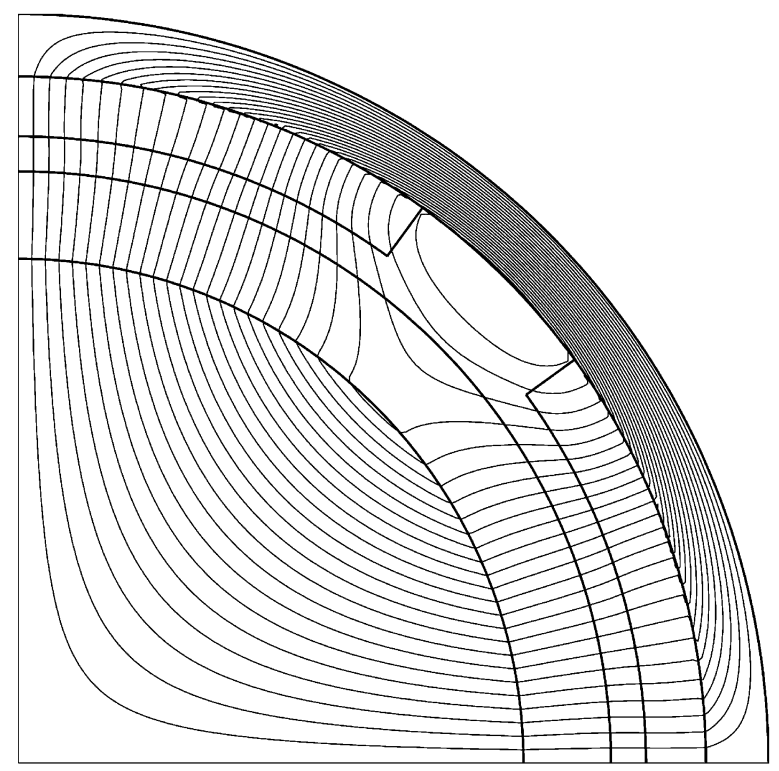

Fig. 6. Magnetic field lines due to radial permanent-magnet array excitation.

the particular solution for the $\nu$ th region has the same Fourierseries form as (20a)

$$
A_{\text {part }, z}^{(\nu)}(r, \phi)=\sum_{k=1,3,5, \cdots}^{\infty} \hat{A}_{\text {part }, z, k}^{(\nu)}(r) \sin (k p \phi) .
$$

Therefore, the solution to Poisson's equation (18) can be written as

$$
A_{z}^{(\nu)}(r, \phi)=\sum_{k=1,3,5, \cdots}^{\infty} \hat{A}_{z, k}^{(\nu)}(r) \sin (k p \phi)
$$

where

$$
\hat{A}_{z, k}^{(\nu)}(r)=C_{k}^{(\nu)}\left(\frac{r}{r_{\nu}}\right)^{-k p}+D_{k}^{(\nu)}\left(\frac{r}{r_{\nu}}\right)^{k p}+\hat{A}_{\mathrm{part}, z, k}^{(\nu)}(r) .
$$

Since the permanent magnets form layer $5, \nu=5$ is used in (21) and (22).

The 12 boundary condition constants $C_{k}^{(\nu)}, D_{k}^{(\nu)}, \nu=$ $1,2, \ldots, 6$ are obtained in three steps:

1) convert the solutions to $A_{z}$ [listed above as (20) and (22)] into expressions for $B_{r}, B_{\phi}, H_{r}$, and $H_{\phi}$ by means of (6b) and (8);

2) substitute these expressions into the boundary conditions (14) and (15); and

3) solve the 12 equations obtained from step 2 for the boundary condition constants.

\section{Solution Results}

Space does not permit a full listing of the boundary condition constants; these may be obtained from [2]. Results of the solution are presented graphically in Figs. 6 and 7.

Fig. 6 shows the magnetic field lines obtained directly from the vector potential solutions of (20) and (22). The tangential 


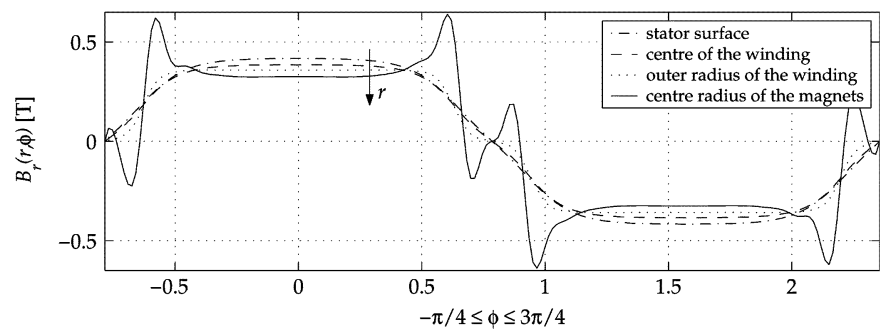

(a)

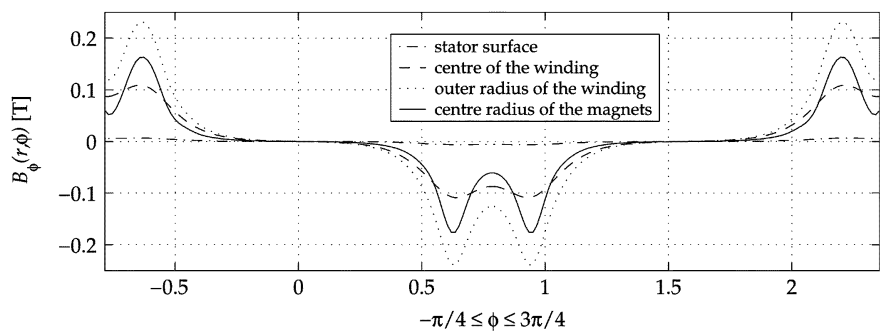

(b)

Fig. 7. (a) Radial and (b) tangential components of the flux density at several different radii due to radial permanent-magnet array excitation.

span of the permanent magnets in the solution was set to fill $80 \%$ of the machine's circumference. Only one quarter of the machine is shown due to symmetry. The machine in Fig. 6 has four poles.

The radial and tangential components of the flux density at several different radii are shown in Fig. 7 as a function of $\phi$, the rotor angular coordinate.

\section{Field of THE StATor CURRENTS}

\section{A. The Poisson Equation for Stator Current Excitation}

When solving for the magnetic field due to the stator currents, the term $\nabla \times \mathbf{B}_{\text {rem }}$ in (13) is set to zero. ${ }^{2}$ By use of assumptions 1 and 2 in Section II-B, the Poisson equation (13) becomes

$$
\frac{\partial^{2} A_{z}}{\partial r^{2}}+\frac{1}{r^{2}} \frac{\partial^{2} A_{z}}{\partial \phi^{2}}+\frac{1}{r} \frac{\partial A_{z}}{\partial r}+\mu \sigma \frac{\partial A_{z}}{\partial t}=-\mu J_{s, z}
$$

in cylindrical coordinates. In (23), the current direction is explicitly indicated by the subscript $z$ as being parallel to the $z$-axis.

Referring to Fig. 4, the current density $J_{s, z}$ is nonzero only in region $\nu=2$, while the eddy-current reaction field $\left(\partial A_{z} / \partial t\right)$ is nonzero only in region $\nu=4$ (inside the shielding cylinder). In the other four regions, (23) simplifies to the Laplace equation (19). The solution of the magnetic field in the machine due to the stator currents including the eddy currents in the shielding cylinder is found in a similar manner as described in Section III for the permanent magnets.

\section{B. The Stator Current Density}

An expression for the current density in region $\nu=2$ in (23) is needed before a solution can be attempted. For phase $a$ such

\footnotetext{
${ }^{2}$ The machine design has been carefully done so that no iron parts are driven close to saturation to limit iron losses. If the iron does not saturate, a superposition-type approach where the field due to the permanent magnets and that due to the stator currents is treated separately, is a valid one.
}

an expression can be written as

$$
J_{s a}(\varphi, t)=\frac{n_{s a}(\varphi) i_{s a}(t)}{h_{w} r_{w c}}
$$

where $n_{s a}(\varphi)$ is the winding distribution, $i_{s a}(t)$ is the phase current, $h_{w}$ is the height of the winding, and $r_{w c}=\left(r_{w}+\right.$ $\left.r_{s o}\right) / 2$ is the radius in the center of the winding. Similar expressions for phases $b$ and $c$ are written, with the customary phase shift in both time and position. The total current density in the machine is then obtained as $J_{s, z}(\varphi, t)=J_{s a}(\varphi, t)+$ $J_{s b}(\varphi, t)+J_{s c}(\varphi, t)$. The stator current $i_{s a}(t)$ in (24) is written as a Fourier series to include any time harmonic components that may be present in the waveform. Similarly, the winding distribution $n_{s a}(\varphi)$ is written to include the space harmonic components of the winding (obtained from the winding factors). Therefore, the current density includes both space and time harmonic components and the solution to (23) may be written in component form; the total solution to the magnetic field will then be the sum over all the space- and time harmonic component solutions.

The space harmonic number is indicated by $k$; it can be written as $k \equiv 6 \ddot{k}+1 ; \ddot{k} \in \mathcal{Z}$. Similarly, $n \equiv 6 \ddot{n}+1 ; \ddot{n} \in \mathcal{Z}$ where $n$ is the time harmonic number. This is done to eliminate triplen harmonics (only balanced three-phase conditions are considered in the paper). By following this reasoning and some algebra, the expression for the $k$ th space and $n$th time harmonic of the total current density in the machine can be written in the rotor reference frame as

$$
\begin{aligned}
& J_{s, 6 \ddot{k}+1,6 \ddot{n}+1}(\phi, t) \\
& =\left\{\frac{3}{2} \frac{\hat{n}_{s, 6 \ddot{k}+1} \hat{i}_{s, 6 \ddot{n}+1}}{h_{w} r_{w c}}\right\} \mathrm{e}^{-j\left[(6 \ddot{k}+1) p \phi+6(\ddot{k}-\ddot{n}) \omega_{s} t+p \theta_{0}\right]}
\end{aligned}
$$

where $\theta_{0}$ is the initial rotor positional angle and $\omega_{s}$ the fundamental stator electrical frequency.

\section{Form of the Solution}

1) Solution in the Shielding Cylinder: By substituting (25) into (23) and working through the mathematical steps, the following solution of the vector potential in the shielding cylinder $(\nu=4)$ is obtained:

$$
\begin{aligned}
& \bar{A}_{z, 6 \ddot{k}+1,6 \ddot{n}+1}^{(4)}(r, \phi, t) \\
& =\hat{\bar{A}}_{z, 6 \ddot{k}+1,6 \ddot{n}+1}^{(4)}(r)\left\{\frac{3}{2} \frac{\hat{n}_{s, 6 \ddot{k}+1} \hat{i}_{s, 6 \ddot{n}+1}}{h_{w} r_{w c}}\right\} \\
& \quad \times \mathrm{e}^{-j\left[(6 \ddot{k}+1) p \phi-6(\ddot{n}+1) \omega_{s} t\right]} ; \\
& \hat{\bar{A}}_{z, 6 \ddot{k}+1,6 \ddot{n}+1}^{(4)}(r)=\bar{C}_{6 \ddot{k}+1,6 \ddot{n}+1}^{(4)} I_{6 \ddot{k}+1}\left(\bar{\tau}_{6 \ddot{n}+1} r\right) \\
& \quad+\bar{D}_{6 \ddot{k}+1,6 \ddot{n}+1}^{(4)} K_{6 \ddot{k}+1}\left(\bar{\tau}_{6 \ddot{n}+1} r\right) .
\end{aligned}
$$

Equation (26) is obtained for a locked rotor; the solution for a synchronlously rotating rotor is slightly more complicated but similar (see [2]). In (26b), the functions $I_{6 \ddot{k}+1}$ and $K_{6 \ddot{k}+1}$ are modified Bessel functions of the first and second kind of order $6 \ddot{k}+1$, respectively. The bar introduced above the symbols in (26) indicates complex quantities. The constants $\bar{C}_{6 \ddot{k}+1,6}^{(4)}$ $6 \ddot{k}+1,6 \ddot{n}+1$ 


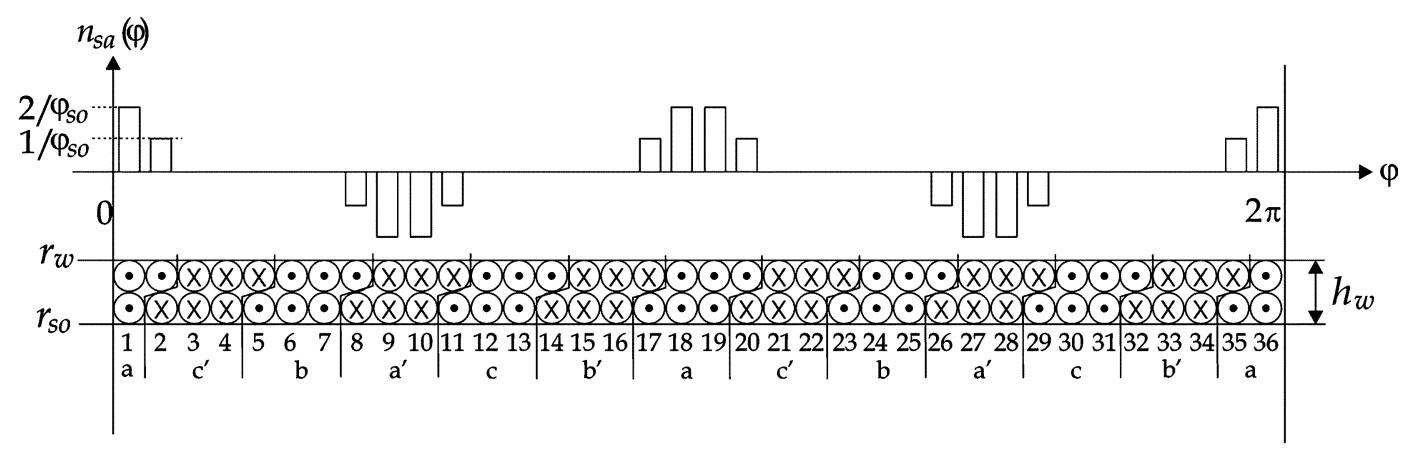

Fig. 8. Linear depiction of the winding distribution of the flywheel machine of Fig. 2. The winding distribution of phase $a, n_{s a}(\varphi)$, is also shown.

and $\bar{D}_{6 \ddot{k}+1,6 \ddot{n}+1}^{(4)}$ are complex constants determined from the boundary conditions. The final undefined constant in (26) is $\bar{\tau}_{6 \ddot{n}+1}^{2} \equiv j \mu \sigma(6 \ddot{n}+1) \omega_{s}$.

2) Solution in the Winding Region: The solution in the winding region $(\nu=2)$ for a locked rotor is of the form

$$
\begin{aligned}
& \bar{A}_{z, 6 \ddot{k}+1,6 \ddot{n}+1}^{(2)}(r, \phi, t) \\
& =\hat{\bar{A}}_{z, 6 \ddot{k}+1,6 \ddot{n}+1}^{(2)}(r)\left\{\frac{3}{2} \frac{\hat{n}_{s, 6 \ddot{k}+1} \hat{i}_{s, 6 \ddot{n}+1}}{h_{w} r_{w c}}\right\} \\
& \quad \times \mathrm{e}^{-j\left[(6 \ddot{k}+1) p \phi-6(\ddot{n}+1) \omega_{s} t\right]} ; \\
& \hat{\bar{A}}_{z, 6 \ddot{k}+1,6 \ddot{n}+1}^{(2)}(r)=\bar{C}_{6 \ddot{k}+1,6 \ddot{n}+1}^{(2)}\left(\frac{r}{r_{2}}\right)^{-|6 \ddot{k}+1| p} \\
& \quad+\bar{D}_{6 \ddot{k}+1,6 \ddot{n}+1}^{(2)}\left(\frac{r}{r_{2}}\right)^{|6 \ddot{k}+1| p}+\hat{\bar{A}}_{\mathrm{part}, z, 6 \ddot{k}+1}^{(2)}(r) .
\end{aligned}
$$

The particular solution in (27b) is

$$
\hat{\bar{A}}_{\text {part }, z, 6 \ddot{k}+1}^{(2)}(r)= \begin{cases}\frac{\mu r^{2}}{[(6 \ddot{k}+1) p]^{2}-4}, & \text { if }(6 \ddot{k}+1) p \neq 2 \\ \frac{1}{4} \mu r^{2}\left(-\ln (r)+\frac{1}{4}\right), & \text { if }(6 \ddot{k}+1) p=2 .\end{cases}
$$

Space does not permit the full listing of the boundary condition constants in the above equations; for more details, see [2]. The solutions in the other regions (layers) in the machine are similar to those discussed above.

\section{Solution Results}

1) A Typical Winding Distribution: The results of the calculation of the magnetic field due to the stator currents are presented in this section for the winding distribution shown in Fig. 8. This is an example of a typical winding distribution that can be used in the slotless machine: it has two layers with the top layer short-pitched by one slot.

2) Snapshot of the Magnetic Field in the Air Gap: A time instant $\tilde{t}$ exists in a balanced three-phase winding where $i_{s a}(\tilde{t})=$ $0 \mathrm{~A}$ and $i_{s b}(\tilde{t})=-i_{s c}(\tilde{t})=\tilde{i} \mathrm{~A}$, where $\tilde{i}$ is some value of current. Fig. 9 shows a snapshot at such an instant for a locked rotor; the calculated magnetic field (radial component) at several machine radii is shown as a function of the stator angular coordinate $\varphi$. (The value used for the current in the flywheel machine at this instant was $\tilde{i}=260$ A.)

The effect of the slots on the field can be clearly seen. The effect is, however, much smaller than in an equivalent slotted machine.

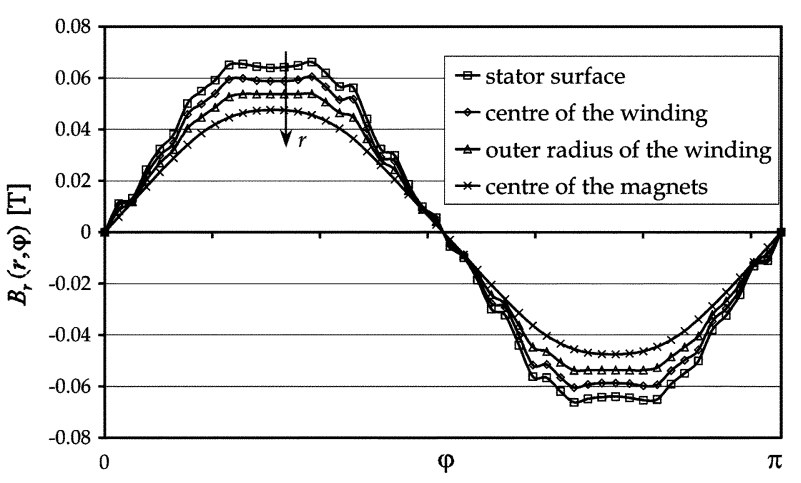

Fig. 9. Radial component of the flux density at several different radii for a locked rotor due to the currents $i_{s a}=0, i_{s b}=260 \mathrm{~A}=-i_{s c}$ flowing in the air gap winding.

3) Field Plot of Shielding Effect: Fig. 10 shows the calculated magnetic field lines due to the stator currents in the machine for a synchronously rotating rotor. In Fig. 10(a), the fundamental space and time harmonic component of the field is shown: it completely penetrates the permanent-magnet region. Fig. 10(b) shows the result for the fundamental space harmonic and the fifth time harmonic: in this case the shielding cylinder shields the permanent magnets from this component of the stator currents.

\section{Stator Voltage Equation}

The stator voltage equation is

$$
\begin{aligned}
\vec{u}_{s}(t) & =R_{d c} \vec{i}_{s}(t)+\sum_{\ddot{k}=-\infty}^{\infty} \sum_{\ddot{n}=-\infty}^{\infty} R_{s, 6 \ddot{k}+1,6 \ddot{n}+1} \vec{i}_{s, 6 \ddot{n}+1}(t) \\
& +\vec{e}_{p a}(t)+\sum_{\ddot{k}=-\infty}^{\infty} \sum_{\ddot{n}=-\infty}^{\infty} L_{s s, 6 \ddot{k}+1,6 \ddot{n}+1} \frac{d}{d t} \vec{i}_{s, 6 \ddot{n}+1}(t) \\
& +L_{s \sigma} \frac{d \vec{i}_{s}(t)}{d t}
\end{aligned}
$$

where it can be seen that both the resistance and inductance of the machine have space and time harmonic components. The voltages and current is written in a vector form (a compact form to write the three phase components); i.e., $\vec{u}_{s}(t)=\left(u_{s a}(t) u_{s b}(t) u_{s c}(t)\right)^{T}$. Two quantities in (29) do not have space and time harmonic components: the stator DC resistance $R_{d c}$ and the stator end-winding leakage inductance $L_{s \sigma}$. (The end-winding leakage inductance is, of course, a 


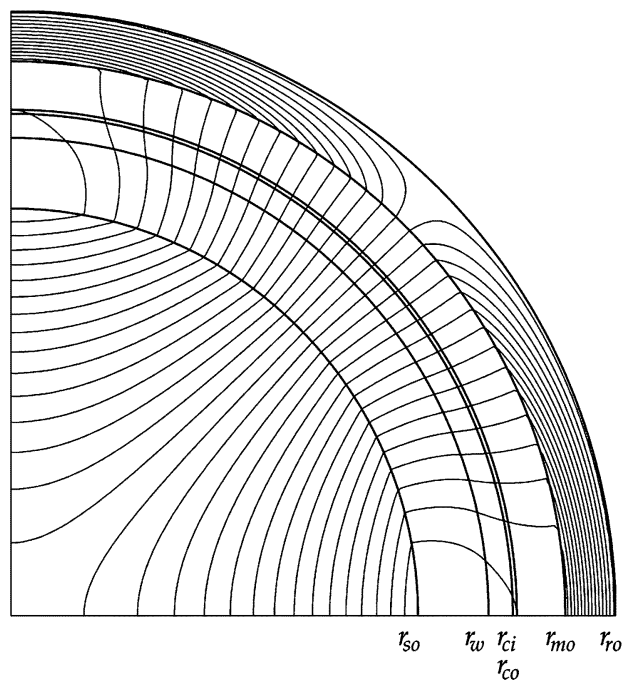

(a)

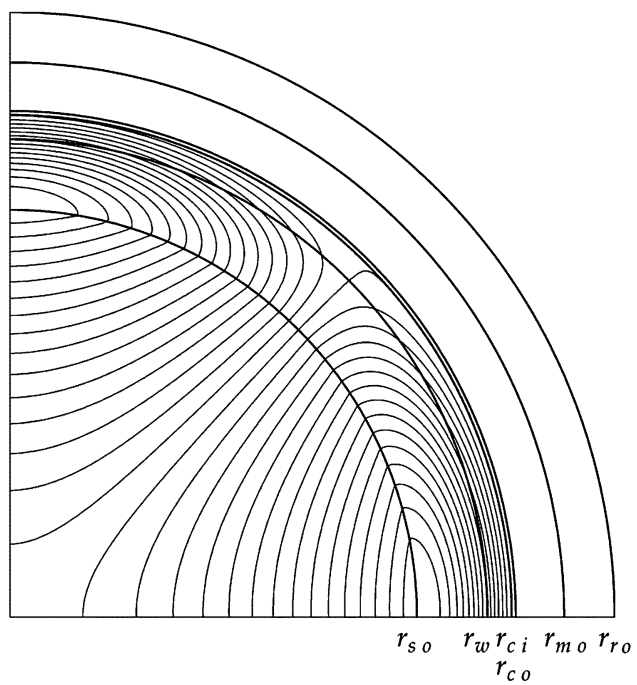

(b)

Fig. 10. Magnetic field lines for a synchronously rotating rotor due to AC stator currents in the air gap winding, including the eddy-current reaction field of the shielding cylinder. (a) $k=1, n=1$. (b) $k=1, n=5$.

function of frequency and consequently the time harmonic, but this is not modeled in this paper.)

The part of the machine resistance and inductance in (29) that are functions of the space and time harmonics will now be discussed in more detail.

\section{A. The Stator Main-Field Inductance}

The stator main-field flux linkage may be written directly as a function of the magnetic vector potential, as was shown in (17) for a single, full-pitch turn. The $k$ th space and $n$th time harmonic component of the three-phase flux linkages in the machine are given by the vector equation

$$
\vec{\lambda}_{s s, 6 \ddot{k}+1,6 \ddot{n}+1}(t)=L_{s s, 6 \ddot{k}+1,6 \ddot{n}+1} \vec{i}_{s, 6 \ddot{n}+1}(t)
$$

where $L_{s s, 6 \ddot{k}+1,6 \ddot{n}+1}$ is a scalar, not a matrix; this is because a symmetrical three-phase system is assumed. The stator main-
TABLE I

THE $k$ TH AND $n$ TH COMPONENT OF THE MAIN-FIELD INDUCTANCE $L_{s s}[\mu \mathrm{H}]$ FOR THE FLYWHEEl MaChINE, CALCUlated From (31)

\begin{tabular}{|c||c|c|c|c|c|c|c|}
\hline$k \backslash n$ & 1 & 5 & 7 & 11 & 13 & 17 & 19 \\
\hline \hline 1 & 38.42 & 4.649 & 4.647 & 4.641 & 4.638 & 4.631 & 4.627 \\
\hline 5 & 0.0338 & 0.0729 & 0.0339 & 0.0338 & 0.0338 & 0.0337 & 0.0337 \\
\hline 7 & 0.0032 & 0.0032 & 0.0054 & 0.0032 & 0.0032 & 0.0032 & 0.0032 \\
\hline 11 & 0.0009 & 0.0009 & 0.0009 & 0.0012 & 0.0009 & 0.0009 & 0.0009 \\
\hline 13 & 0.0024 & 0.0024 & 0.0024 & 0.0024 & 0.0029 & 0.0024 & 0.0024 \\
\hline 17 & 0.0205 & 0.0205 & 0.0205 & 0.0205 & 0.0205 & 0.0225 & 0.0205 \\
\hline 19 & 0.0061 & 0.0061 & 0.0061 & 0.0061 & 0.0061 & 0.0061 & 0.0065 \\
\hline
\end{tabular}

field inductance appears in (30). Its $k$ th space and $n$th time harmonic component is given by

$$
L_{s s a, 6 \ddot{k}+1,6 \ddot{n}+1}=\pi l_{s}\left\{\frac{3}{2} \frac{\hat{n}_{s, 6 \ddot{k}+1}^{2}}{h_{w} r_{w c}}\right\} \hat{A}_{z, 6 \ddot{k}+1,6 \ddot{n}+1}^{(2)}\left(r_{w c}\right)
$$

for phase $a$. The location where the magnetic vector potential is calculated to find the inductance is at the center of the winding: $r=r_{w c}$.

The inductance of (31) includes that part of inductance that is custromarily known as the slot leakage inductance. Since the winding is slotless, the 2-D field calculation already includes this part with the main-field inductance of (31). The only part of leakage inductance that is not included in (31) is the endwinding leakage inductance, which is not modeled analytically in this paper. (It is measured and taken to be a constant: see Section VI.)

Table I lists the space and time harmonic components of the stator main-field inductance. The space harmonic components are listed in the rows and the time harmonic components in the columns. It can clearly be seen that the space harmonics only have a small influence on the inductance; the fifth space harmonic component for $n=1$ is approximately 1000 times smaller than the fundamental space harmonic component, and even smaller for the higher space harmonics. This is due to the fact that the winding is situated in the air gap on a slotless stator.

One can also see from Table I that the inductance changes to a lower value when the frequency changes from the first time harmonic to the fifth, and then stays fairly constant for the time harmonic components above the fifth. This is due to the fact that the shielding cylinder completely shields at the fifth time harmonic, as can be seen also from Fig. 10. Any increase in frequency above this does not significantly change the shielding effect.

The calculation of the machine inductance will be experimentally verified in Section VI.

\section{B. Space and Time Harmonic Dependent Stator Resistance}

In (29), two parts of the stator resistance were shown to exist: 1) the DC resistance of the stator $R_{\mathrm{dc}}$ and 2) a space and time harmonic dependent part of the stator resistance $R_{s, 6 \ddot{k}+1,6 \ddot{n}+1}$. This latter part of the resistance is due to a combination of effects originating from both the stator and the rotor. The first effect that plays a role is of course the spatial distribution of the stator current field. The second effect is the frequency-dependent shielding of the shielding cylinder, which causes a time-harmonic dependent resistance to be reflected to 


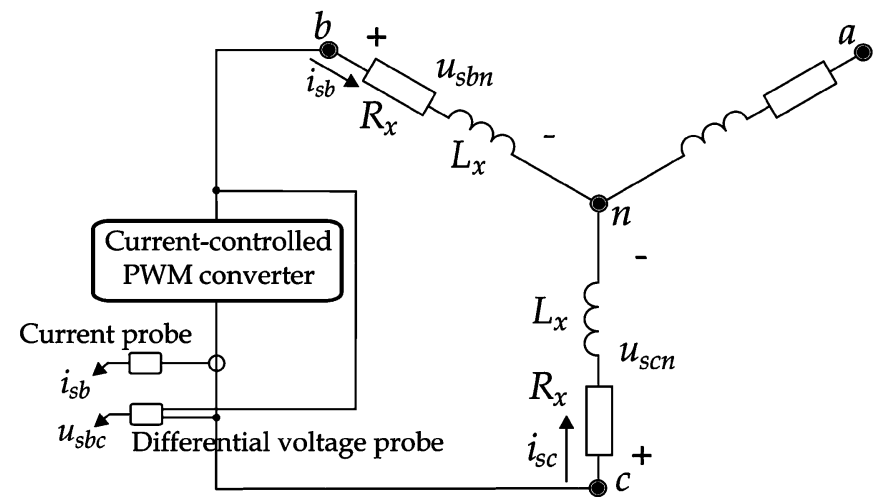

Fig. 11. Circuit diagram for measuring machine impedance with controlled current injection.

the stator. (The Litz strands in the stator winding were made so thin that all frequency-dependent resistance effects on the winding itself are negligible.) Since a resistance constitutes dissipated power, the method for calculating $R_{s, 6 \ddot{k}+1,6 \ddot{n}+1}$ is by means of the Poynting vector. Section VI discusses a calculation of the resistance for the locked-rotor case and its experimental validation.

\section{EXPERIMENTAL RESULTS}

\section{A. Measurement of the Locked-Rotor Machine Impedance}

The experimental verification of the analytical model (by means of the locked-rotor machine impedance) is discussed in this section. The measurement setup used in the experiment is shown in Fig. 11. A current is injected into the stator winding from a PWM converter (the method is dubbed the controlled current injection (CCI) method). The voltage waveform applied to the machine terminals only contains certain harmonics (the fundamental switching frequency plus its harmonic components), but the experiment can be performed at several appropriately chosen frequencies to obtain results for a large bandwidth. Fig. 11 shows the circuit diagram for this method.

For low frequencies, a square wave current was modulated by the converter, while at high frequencies (higher than $500 \mathrm{~Hz}$ ), the current ripple was used directly. Thus, for fundamental frequencies below $500 \mathrm{~Hz}$, the fundamental and third, fifth, seventh, ..., harmonic components were present in the current waveform and for fundamental frequencies higher than $500 \mathrm{~Hz}$, even harmonics were also present.

The converter is simply shown as a block in Fig. 11, although it included a series inductor for frequencies below $500 \mathrm{~Hz}$ and a series inductor and capacitor for frequencies above $500 \mathrm{~Hz}$. The current levels varied from a $50 \mathrm{~A}$ peak value at low frequencies (square wave) to a peak value of $4 \mathrm{~A}$ (triangular waveform) at high frequencies.

As shown in Fig. 11, the line-line voltage $u_{s b c}(t)$ and the line current $i_{s b}(t)$ were measured, sampled and recorded onto disk for the different switching frequencies. Hereafter, the FFT algorithm was used to transform the signals into the frequency domain: $\bar{U}_{s b c}(f)$ and $\bar{I}_{s b}(f)$. The machine impedance at frequency $f$ is then given by

$$
\bar{Z}(f)=\frac{\bar{U}_{s b c}(f)}{\bar{I}_{s b}(f)}
$$

and from Fig. 11 the impedance is also equal to

$$
\bar{Z}(f)=2 R_{x}(f)+4 j \pi f L_{x}(f) .
$$

Therefore, the per-phase resistance and inductance can be calculated from (33) as

$$
R_{x}(f)=\frac{1}{2} \operatorname{Re}\left(\bar{Z}_{x}(f)\right)
$$

and

$$
L_{x}(f)=\frac{1}{4 \pi f} \operatorname{Im}\left(\bar{Z}_{x}(f)\right)
$$

respectively. It is important to note that the $f$ above indicates a vector of discrete frequencies contained in the injected waveforms. The measured resistance and inductance are functions of this frequency vector.

\section{B. Calculation of the Locked-Rotor Machine Impedance by Means of the Analytical Model}

1) Resistance: The average dissipated power on the shielding cylinder is extensively discussed and calculated in [2] as

$$
\left\langle P_{\text {diss }, s c, 6 \ddot{k}+1}(f)\right\rangle=-\operatorname{Re}\left\{\oint_{S} \hat{\overline{\mathbf{S}}}_{6 \ddot{k}+1}(f) \cdot d \mathbf{a}\right\}
$$

where $\hat{\overline{\mathbf{S}}}$ is the average Poynting vector

$$
\hat{\overline{\mathbf{S}}} \equiv \frac{1}{2}\left(\hat{\overline{\mathbf{E}}} \times \hat{\mathbf{H}}^{*}\right) \quad\left[\mathrm{W} / \mathrm{m}^{2}\right]
$$

A bar above the symbol indicates that it is a complex quantity: $\overline{\mathbf{S}}$. The hat above the symbol is used to indicate the peak value of the time-harmonic form: $\hat{\overline{\mathbf{S}}}$. The fact that (37) is an average value is explicitly indicated on the left-hand side by the brackets \langle\rangle . The star in (37) indicates the complex conjugate.

The electric and magnetic field intensities in (37) are both found directly from the magnetic vector potential. Therefore, the power dissipated in die shielding cylinder may be written directly in terms of the vector potential as

$$
\begin{gathered}
\left\langle P_{\text {diss }, s c, 6 \ddot{k}+1}(f)\right\rangle=\operatorname{Re}\left\{\frac{\pi r l_{s}}{\mu_{0}}(j 2 \pi f)\left\{\frac{3}{2} \frac{\hat{n}_{s, 6 \ddot{k}+1} \hat{i}_{s}(t)}{h_{w} r_{w c}}\right\}^{2}\right. \\
\left.\cdot\left(\hat{\bar{A}}_{z, 6 \ddot{k}+1}^{(4)}\left(r_{c i}, f\right)\right)\left[\frac{\partial}{\partial r}\left(\hat{\bar{A}}_{z, 6 \ddot{k}+1}^{(4)}\left(r_{c i}, f\right)\right)\right]^{*}\right\} \cdot
\end{gathered}
$$

The calculation is done at the inner radius of the shielding cylinder: $r=r_{c i}$; the calculation region is just inside the 
shielding cylinder: $\nu=4$. From the dissipated power of (38), an equivalent per-phase resistance may be defined as

$$
R_{s, 1 \phi, 6 \ddot{k}+1}(f)=\frac{2}{3} \frac{\left\langle P_{\text {diss }, s c, 6 \ddot{k}+1}(f)\right\rangle}{|\hat{\bar{i}}(f)|^{2}}
$$

where $\hat{\bar{i}}(f)$ is an equivalent peak current, conveniently chosen as $1 \mathrm{~A}$.

2) Inductance: The constant $\bar{\tau}_{6 \ddot{n}+1}^{2} \equiv j \mu \sigma(6 \ddot{n}+1) \omega_{s}$ introduced in Section IV-C1 is changed into a continuous function of frequency: $\bar{\tau}^{2}(f)=j \mu \sigma 2 \pi f$. This changes the $k$ th space harmonic of the per-phase inductance into

$$
L_{s s a, 6 \ddot{k}+1}(f)=\pi l_{s}\left\{\frac{3}{2} \frac{\hat{n}_{s, 6 \ddot{k}+1}^{2}}{h_{w} r_{w c}}\right\} \hat{A}_{z, 6 \ddot{k}+1}^{(2)}\left(r_{w c}, f\right)
$$

which is a continuous function of $f$.

\section{Comparison}

The results of (34) and (35) represent the measured lockedrotor machine impedance. They may be directly compared to the values obtained by (39) and (40), which represent the analytically calculated locked-rotor machine impedance. The results are shown in Fig. 12.

1) Resistance: The value of $R_{x}(f)$ measured with the CCI method is shown in Fig. 12(a) as stars $(*)$. Each star corresponds either to a fundamental or higher harmonic frequency injected into the stator during the frequency-sweeped test.

The dc resistance is simply a constant for all $f$; it was measured and calculated as $2.566 \mathrm{~m} \Omega$ per phase at room temperature. This value was added to the analytically calculated $R_{s, s c}$ (the reflected resistance due to the eddy currents in the shielding cylinder) in Fig. 12(a).

At higher frequencies (around $300 \mathrm{~Hz}$ ), $R_{d c}+R_{s, s c}$ [the dashed line in Fig. 12(a)] is not an accurate model of the stator resistance anymore. This is due to the frequency-dependent stator iron losses. A simple mathematical model for total iron losses suggested by Polinder [10] predicts the stator resistance at high frequencies as well. The total stator iron losses is modeled as being proportional to (frequency) $)^{3 / 2}$. The resistance component due to the frequency-dependent total stator iron losses, $R_{s, \text { statorFe,tot, }}$ is shown as a chained line $(-\cdot-\cdot-)$ in Fig. 12(a). The total stator resistance is given by $R_{s}(f)+R_{\mathrm{dc}}=R_{s, s c}(f)+R_{s, \text { statorFe,tot }}(f)+R_{\mathrm{dc}}$, and shown as the solid line in Fig. 12(a). It can be seen that it corresponds quite well with the measured $R_{x}(f)$.

2) Inductance: Similar to $R_{x}(f)$, the per-phase inductance $L_{x}(f)$, measured with the CCI method, is shown in Fig. 12(b) as stars $(*)$.

The leakage inductance of the machine consists of two components: the end-winding leakage and the air-gap leakage inductance. Of the two, the end-winding leakage inductance could not be modeled by the analytical model since the model is two dimensional and the end windings are in the third dimension. The inductance predicted by the model therefore consists of a leakage and a main-field component. The measured inductance also consists of these components, and they cannot be separated

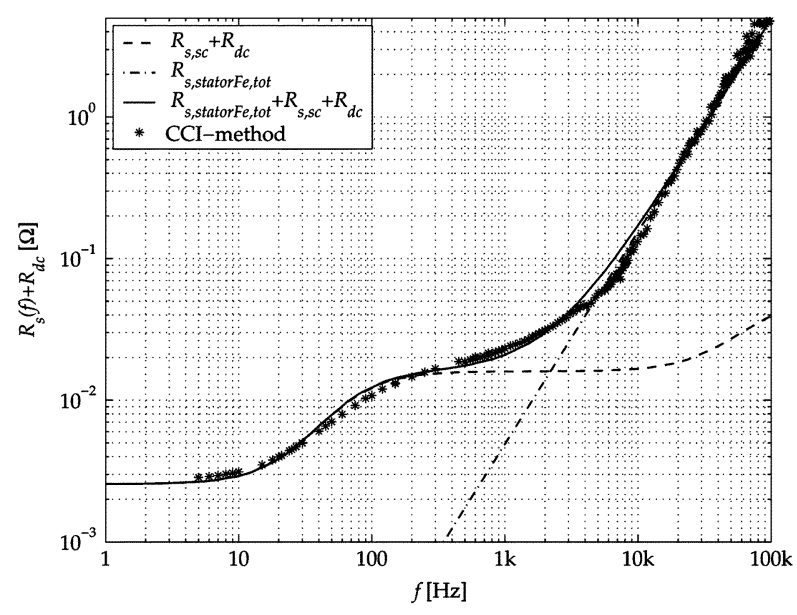

(a)

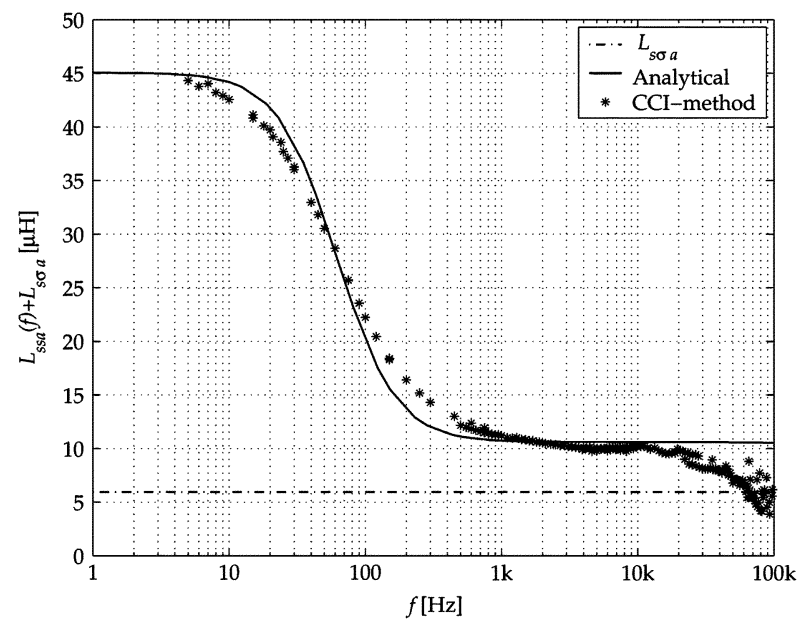

(b)

Fig. 12. Comparison of results of the analytically calculated and the measured impedance. (a) Per-phase resistance. (b) Per-phase inductance.

experimentally. The leakage inductance $L_{s \sigma a}$ is taken to be the frequency-independent difference between the measured $L_{x}(f)$ and the analytically predicted per-phase inductance $L_{s s a}(f)$ : this difference is $L_{s \sigma a}=6.5 \mu \mathrm{H}$.

From Fig. 12(b) it can be seen that $L_{x}(f)$ and $L_{s}(f)=$ $L_{s \sigma a}+L_{s s a}(f)$ agree quite well over a large range of frequencies, except at $f>20 \mathrm{kHz}$. The difference at these high frequencies may be attributed to the skin and proximity effects in the Litz conductors of the stator winding.

Fig. 12(b) also shows that there are essentially two values of inductance with a transition between them. One is the low-frequency inductance $(45 \mu \mathrm{H})$, which is the inductance where the shielding cylinder does not shield at all. The other is the highfrequency inductance $(11 \mu \mathrm{H})$, which is the inductance where the shielding cylinder shields completely. This high-frequency inductance is the one to consider when matching the machine to a converter since it determines the maximum current during the converter's commutation.

\section{CONCLUSION}

The objective of this paper was to present a comprehensive analytical model of the flywheel permanent-magnet machine 
presented in Section I-A. This has been succesfully accomplished. The motivation for using the analytical approach in stead of finite elements was discussed: it requires less computational time, leads to greater insight, and the flywheel machine topology lends itself to such an approach. The paper extensively surveyed literature on analytical field calculations in permanent-magnet machines. This led to the identification of where a contribution can be made: the analytical solution of the two-dimensional magnetic field in the six-layer system required for this machine topology. The analytical model accounts for the fact that the winding is in the air gap and also includes the reaction field of the eddy currents on the shielding cylinder. The space and time harmonic dependent machine resistance and inductance were derived directly from the magnetic vector potential. These were experimentally validated on a prototype flywheel machine and good agreement was obtained.

\section{ACKNOWLEDGMENT}

The authors would like to thank Dr. ir. M. Hoeijmakers for many productive discussions on analytical field calculations, as well as the Centre for Concepts in Mechatronics (CCM) B.V. of Nuenen, the Netherlands, the industrial partner for this project. CCM did all the mechanical, power electronic, auxiliary and control systems design work, as well as the actual construction of the flywheel energy system.

\section{REFERENCES}

[1] W. D. Jones, "Hybrids to the rescue," IEEE Spectr., Jan. 2003.

[2] S. R. Holm, "Modelling and optimization of a permanent-magnet machine in a flywheel," Ph.D. dissertation, Delft Univ. Technol., Delft, The Netherlands, Nov. 2003.

[3] G. Genta, Kinetic Energy Storage-Theory and Practice of Advanced Flywheel Systems. $\quad$ London, U.K.: Butterworths, 1985, ISBN 0-40801396-6.

[4] P. P. Acarnley, B. C. Mecrow, J. S. Burdess, J. N. Fawcett, J. G. Kelly, and P. G. Dickinson, "Design principles for a flywheel energy store for road vehicles," IEEE Trans. Ind. Appl., vol. 32, no. 6, pp. 1402-1408, Nov./Dec. 1996.

[5] F. Şahin, "Design and development of a high-speed axial-flux permanent-magnet machine," Ph.D. dissertation, Eindhoven Univ. Technol., , May 2001.

[6] F. J. M. Thoolen, "Development of an advanced high speed flywheel energy storage system," Ph.D. dissertation, Eindhoven Univ. Technol., Eindhoven, The Netherlands, Dec. 1993.

[7] A. A. Arkadan, R. Vyas, J. G. Vaidya, and M. J. Sha, "Effect of toothless stator design on core and stator conductors eddy current losses in permanent magnet generators," IEEE Trans. Energy Convers., vol. 7, no. 1, Mar. 1992.

[8] J. L. F. v. d. Veen, L. J. J. Offringa, and A. J. A. Vandenput, "Minimizing rotor losses in high-speed high-power permanent magnet synchronous generators with rectifier load," in IEE Proc.-Electr. Power Appl., Sep. 1997, vol. 144, no. 5, pp. 331-337.

[9] S. M. A. Sharkh, M. R. Harris, and N. T. Irenji, "Calculation of rotor eddy-current loss in high-speed PM alternators," in Conf. Rec., Int. Conf. Electrical Machines and Drives (EMD 1997), 1997, pp. 170-174.

[10] H. Polinder, "On the losses in a high-speed permanent magnet generator with rectifier," Ph.D. dissertation, Faculty ITS, Delft Univ. Technol., Delft, The Netherlands, Jun. 1998.

[11] Z. Q. Zhu, K. Ng, N. Schofield, and D. Howe, "Analytical prediction of rotor eddy current loss in brushless machines equipped with surfacemounted permanent magnets, part I: Magnetostatic field model," in Proc. Fifth Int. Conf. Electrical Machines and Systems (ICEMS 2001), Sep. 2001, vol. 2, no. 5, pp. 806-810.
[12] _ _ "Analytical prediction of rotor eddy current loss in brushless machines equipped with surface-mounted permanent magnets, Part II: Accounting for eddy current reaction field," in Proc. Fifth Int. Conf. Electrical Machines and Systems (ICEMS 2001), Sep. 2001, vol. 2, no. 5, pp. 810-813.

[13] R. L. Stoll, The Analysis of Eddy Currents. London, U.K.: Oxford Univ. Press, 1974.

[14] B. Hague, Electromagnetic Problems in Electrical Engineering. London, U.K.: Oxford Univ. Press, 1929.

[15] N. Boules, "Two dimensional field analysis of cylindrical machines with permanent magnet excitation," IEEE Trans. Ind. Appl., vol. IA-20, pp. 1267-1277, 1984.

[16] P. A. Watterson, J. G. Zhu, and V. S. Ramsden, "Optimization of permanent magnet motors using field calculations of increasing precision," IEEE Trans. Magn., vol. 28, no. 2, pp. 1589-1592, Mar. 1992.

[17] Z. Q. Zhu, D. Howe, E. Bolte, and B. Ackermann, "Instantaneous magnetic field distribution in brushless permanent magnet DC motors, Part I: Open-circuit field," IEEE Trans. Magn., vol. 29, no. 1, pp. 124-135, Jan. 1993.

[18] U. Kim and D. K. Lieu, "Magnetic field calculation in permanent magnet motors with rotor eccentricity: Without slotting effect," IEEE Trans. Magn., vol. 34, no. 4, pp. 2243-2252, Jul. 1998.

[19] H. Mosebach, "Einfache analytische rechenmodelle für permanentmag-neterregte synchronmachinen," in Electrical Engineering, ser. 3. Berlin, Germany: Springer-Verlag, 1998, vol. 81, pp. 171-176.

[20] K. F. Rasmussen, J. H. Davies, T. J. E. Miller, M. I. McGilp, and M. Olaru, "Analytical and numerical computaion of air-gap magnetic fields in brushless motors with surface permanent magnets," IEEE Trans. Ind. Appl., vol. 36, no. 6, pp. 1547-1554, Nov./Dec. 2000.

[21] Y. Zhilichev, "Analysis of permanent magnet machines using crossing macro-elements," IEEE Trans. Magn., vol. 36, no. 5, pp. 3122-3124, Sep. 2000.

[22] H. Mosebach, "Direct two-dimensional analytical thrust calculation of permanent magnet excited linear synchronous machines," in Conference Record, 2nd International Symposium on Linear Drives for Industry Applications. Tokyo, Japan: IEE, Japan, Apr. 1998, pp. 396-399.

[23] Z. Q. Zhu and D. Howe, "Instantaneous magnetic field distribution in brushless permanent magnet DC motors, Part II: Armature-reaction field," IEEE Trans. Magn., vol. 29, no. 1, pp. 136-142, Jan. 1993.

[24] —_ "Instantaneous magnetic field distribution in brushless permanent magnet DC motors, Part III: Effects of stator slotting," IEEE Trans. Magn., vol. 29, no. 1, pp. 143-151, Jan. 1993.

[25] _ - "Instantaneous magnetic field distribution in brushless permanent magnet DC motors, Part IV: Magnetic field on load," IEEE Trans. Magn., vol. 29, no. 1, pp. 152-158, Jan. 1993.

[26] Z. Q. Zhu, D. Howe, E. Bolte, and B. Ackermann, "Prediction of opencircuit airgap field distribution in brushless machines having an inset permanent magnet rotor topology," IEEE Trans. Magn., vol. 30, no. 1, pp. 98-107, Jan. 1994

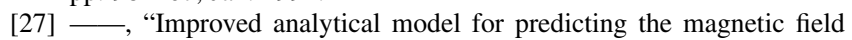
distribution in brushless permanent-magnet machines," IEEE Trans. Magn., vol. 38, no. 1, pp. 229-238, Jan. 2002.

[28] U. Kim and D. K. Lieu, "Magnetic field calculation in permanent magnet motors with rotor eccentricity: With slotting effect considered," IEEE Trans. Magn., vol. 34, no. 4, pp. 2253-2266, Jul. 1998.

[29] A. Hughes and T. J. E. Miller, "Analysis of fields and inductances in air-cored and iron-cored synchronous machines," in Proc. IEE, 1977, vol. 124 , no. 2, pp. 121-126.

[30] H. Polinder, "Analytic calculation of the magnetic field in PM machines," in Conf. Rec., 32nd IEEE Industry Applications Society Conf., New Orleans, LA, Oct. 5-9, 1997, vol. 1, pp. 35-41.

[31] K. Atallah, Z. Q. Zhu, D. Howe, and T. S. Birch, "Armature reaction field and winding inductances of slotless permanent-magnet brushless machines," IEEE Trans. Magn., vol. 34, no. 5, pp. 3737-3744, Sep. 1998.

[32] K. Sridhar, "Electromagmetic models for PM synchronous motor drives," in Conf. Rec., Tenth Annu. Applied Power Electronics Conf. Expo. (APEC 1995), 1995, pp. 367-377.

[33] J. Lammeraner, Eddy Currents. London, U.K.: Iliffe Books, 1966.

[34] C. S. Antonopoulos, S. M. Panas, and E. E. Kriezis, "Transient electromagnetic shielding in a system of two coaxial cylindrical shells," in IEE Proc.-A, Sept. 1991, vol. 138, no. 5, pp. 281-285.

[35] K. Ng, Z. Q. Zhu, and D. Howe, "Open-circuit field distribution in a brushless motor with diametrically magnetized PM rotor, accounting for slotting and eddy current effects," IEEE Trans. Magn., vol. 32, no. 5, pp. 5070-5072, Sep. 1996. 
[36] F. Deng, "Commutation-caused eddy-current losses in permanent-magnet brushless DC motors," IEEE Trans. Magn., vol. 33, no. 5, pp. 4310-4318, Sep. 1997.

[37] F. Deng and T. W. Nehl, "Analytical modeling of eddy-current losses caused by pulse-width modulation switching in permanent-magnet brushless direct-current motors," IEEE Trans. Magn., vol. 34, no. 5, pp. 3728-3736, Sep. 1998.

[38] S. M. A. Sharkh, N. T. Irenji, and M. R. Harris, "Effect of power factor on rotor loss in high-speed PM alternators," in Conf. Rec., Int. Conf. Electrical Machines and Drives (EMD 1999), Sep. 1999, pp. 346-350.

[39] E. Bolte and C. Hahlweg, "Analysis of steady-state performance of high speed induction motors with exterior rotor and conductive layer on the slotted stator," in Conf. Rec., Int. Conf. Electrical Machines (ICEM 2002), Sep. 2002.

[40] H. A. Haus and J. R. Melcher, Electromagnetic Fields and Energy. London, U.K.: Prentice-Hall, 1989.

Manuscript received April 26, 2006; revised November 6, 2006. Corresponding author: S. R. Holm (e-mail: robertholm@ieee.org).

Stanley Robert Holm (M'01) was born in Johannesburg, South Africa, in 1973. He received the B.Eng. and M.Eng. degrees in electrical engineering and the B.Sc.(Hons) degree in applied mathematics from the Rand Afrikaans University, Johannesburg, South Africa, in 1996, 1998, and 1998, respectively, and the Ph.D. degree in electrical engineering from the Delft University of Technology, Delft, the Netherlands, in 2003.

From 1998 to 1999 he worked in industry as a power electronics design engineer, and from 1999 to 2003 he worked as a Ph.D. researcher at the Delft University of Technology. From 2004 to 2006 he was Senior Lecturer at the University of Johannesburg (formerly Rand Afrikaans University). Since July 2006, he has been Associate Professor at the North-West University, Potchefstroom, South Africa. His current research interests include permanent-magnet machines, electromagnetics, and drives.
Henk Polinder (M'97) received the M.Sc. degree in 1992 and the Ph.D. degree in 1998, both in electrical engineering, from the Delft University of Technology, Delft, the Netherlands.

From 1996 to 2003, he was an Assistant Professor, and since 2003, he has been an Associate Professor at the Delft University of Technology in the field of electrical machines and drives. In 1998 and 1999, he was part-time detached at the wind turbine manufacturer Lagerwey to design a direct-drive generator. In 2001, he was part-time detached at Philips CFT. In July and August 2002, he was a visiting scholar at the University of Newcastle-upon-Tyne. He is author and co-author of over 50 papers. His main research interests are design aspects of electrical machines for renewable energy and mechatronic applications.

Jan Abraham Ferreira (M'88-SM'98-F'05) was born in Pretoria, South Africa, in 1958. He received the B.Sc.Eng., M.Sc.Eng., and Ph.D. degrees in electrical engineering from the Rand Afrikaans University, Johannesburg, South Africa, in 1981, 1983, and 1988, respectively.

In 1981 he was with the Institute of Power Electronics and Electric Drives, Technical University of Aachen, and worked in industry at ESD (Pty) Ltd. from 1982 to 1985 . From 1986 until 1997 he was at the Faculty of Engineering, Rand Afrikaans University, where he held the Carl and Emily Fuchs Chair of Power Electronics in later years. Since 1998, he has been a Professor at the Delft University of Technology, Delft, The Netherlands.

During 1993-1994, Dr. Ferreira was chairman of the South African Section of the IEEE. He was the founding chairman of the IEEE Joint IAS/PELS Benelux chapter in 1999. He served as the transactions review chairman of the IEEE IAS Power Electronic Devices and Components Committee during 1999-2003 and is an Associate Editor of the IEEE TRANSACTIONS ONPOWERELECTRONICS. He is a member of the IEEE PESC Adcom and since 2005 has been the treasurer of the IEEE PELS. He served as chairman of the CIGRE SC14 national committee of the Netherlands and was a member of the executive committee of the EPE Society. 